\title{
Spleen-preserving laparoscopic distal pancreatectomy: Two cases and review of the technique
}

\author{
Koray Topgül'1, S. Savaș Yürüker², Bülent Koca², Tuğrul Kesicioğlu²
}

In this study, we aimed to assess the technique and results of spleen-preserving laparoscopic distal pancreatectomy (SPLDP) on the basis of two cases. The first case was a woman with a large cystic papillary lesion of the distal pancreas. The other patient was a woman with a pancreatic mass on the tail of the pancreas. Both patients were operated on using SPLDP. Five trocars were used in the first case and four trocars were used in the second case. Thirty degree telescope visualization and LigaSure dissection were used during the operation. The splenic vessels were dissected, but the short gastric vessels were preserved. The pancreas was transected by one Endo GIA stapler and the cut edge of the pancreas was reinforced with sutures to prevent a pancreatic fistula. We performed the same technique in both cases. However, in the first case, we aspirated the content of the cystic mass of the pancreas before removing it to avoid making a large incision. The duration of the operation was 190 and 135 minutes, respectively. There were no postoperative complications. SPLDP is a safe, effective modality for managing lesions of the distal pancreas. If the splenic vessels are transected, the short gastric vessels must be protected to ensure the viability of the spleen.

Key Words: Pancreatic cyst, spleen-preserving laparoscopic distal pancreatectomy, distal pancreatectomy, laparoscopic pancreatic surgery

'Medical Park Samsun Hospital, Department of General Surgery, Samsun, Turkey

${ }^{2}$ Ondokuz Mayıs University School of Medicine, Department of General Surgery, Samsun, Turkey

\section{Address for Correspondence} Dr. Koray Topgül

Medical Park Samsun Hospital, Department of General Surgery, Samsun, Turkey

Phone: +905324466411

e-mail:

ktopgul@gmail.com

Received: 21.10 .2012

Accepted: 17.05.2013

CCopyright 2013 by Turkish

Surgical Association

Available online at

www.ulusalcerrahidergisi.org

\section{INTRODUCTION}

Minimally invasive procedures are currently being used in a safe and effective way in the surgery of the alimentary tract. Laparoscopic procedures for surgery of the pancreas have been introduced in the first half of the nineties. Gargner and Pomp (1) have done the first laparoscopic pancreaticoduodenectomy in 1994, translating this method that has been experimental to humans. Especially distal pancreatectomy has gained acceptance, with easier application as compared to pancreatoduodenectomy and with not including an anastomosis (2). Laparoscopic distal pancreatectomy (LDP) has been suggested mainly for benign and borderline malign lesions with concerns about the number of lymph nodes that can be harvested and adherence to oncologic principles (3). In addition, malignant lesions are usually accompanied by significant inflammation, peritumoral fibrosis and pancreatitis (4). With the complex retroperitoneal anatomy of pancreas in mind, LDP might be quite difficult.

One of the main points in the application of this technique is the preservation of the spleen during distal pancreatectomy. Undoubtedly, application of LDP with spleen extraction is an easier technique. There is always probability of infectious complications and sepsis, which might be fatal (5). Therefore, spleen has to be preserved as long as there is no indication for splenectomy. In this article, we aimed to present two cases that underwent spleen preserving laparoscopic distal pancreatectomy (SPLDP) and review the details of this technique.

\section{CASE PRESENTATIONS}

\section{Case 1}

A 50-year-old female presented with dyspepsia and bloating complaints for the last 3-4 months. An abdominal computerized tomography (CT) revealed a large cystic mass (75x82 mm) with calcifications, located in the tail of the pancreas, which resulted in her referral to our clinic (Figure 1). She had no medical illness and physical examination was normal. The radiologists classified the lesion as potentially malignant based on its dimension and papillary projections within the cyst. A laparoscopic distal pancreatectomy was planned, without any further evaluation. Her preoperative test results were normal except for anemia, also the glucose level was $160 \mathrm{mg} / \mathrm{dL}$, and tumor markers were normal. 
Technique: The surgeon was placed in the middle between the patient's legs, with the patient lying supine and in reverse Trendelenburg position. Three $5 \mathrm{~mm}$, and two $12 \mathrm{~mm}$ ports were used. The first port was introduced through the umbilicus under direct vision, a $30^{\circ}$ telescope was used. Following exploration the gastrocolic ligament was opened with LigaSure (Covidien ${ }^{\circledR}$ ), the gastroepiploic arcade was preserved. The stomach was lifted against the abdominal wall and anterior pancreas was fully visualized. The Fredet fascia(between the pancreas and mesocolon) was opened and tail of the pancreas was mobilized towards the spleen. During these manipulations, the large cystic mass was mobilized in the up-down or medial- lateral directions. The splenic artery and vein was visualized in the junction of the body and the tail at the upper border of the pancreas. The splenic vein was injured during dissection, therefore both the artery and the vein were ligated. The short gastric vessels were preserved, thus a splenectomy was not considered (Figure 2). The pancreas was transected at the level of body-tail junction with an Endo GIA(Figure 3). The stapled pancreatic stump was re-enforced with sutures by “Endo-stich" (Covidien ${ }^{\oplus}$ ) (Figure 4). After the lesion was freed from its attachments to the spleen, the $12 \mathrm{~mm}$ port was replaced by an $18 \mathrm{~mm}$ port. An endobag was introduced. In order not to make a larger skin incision, the contents of the cyst was aspirated by a syringe. The lesion was easily extracted in this endobag afterwards (Figure 5). A surgical drain was inserted. The operating time was 190 minutes.

Oral diet was initiated on the $2^{\text {nd }}$ postoperative day, the drain removed on the $4^{\text {th }}$ and the patient was discharged on the $7^{\text {th }}$. The speciment was reported to be a solid-papillary neoplasia by pathologists. The abdominal CT did not show any problem regarding the viability of the spleen, infarct or abscess on the $3^{\text {rd }}$ postoperative month (Figure 6). The magnetic resonance imaging (MRI) did not show any pathology in the

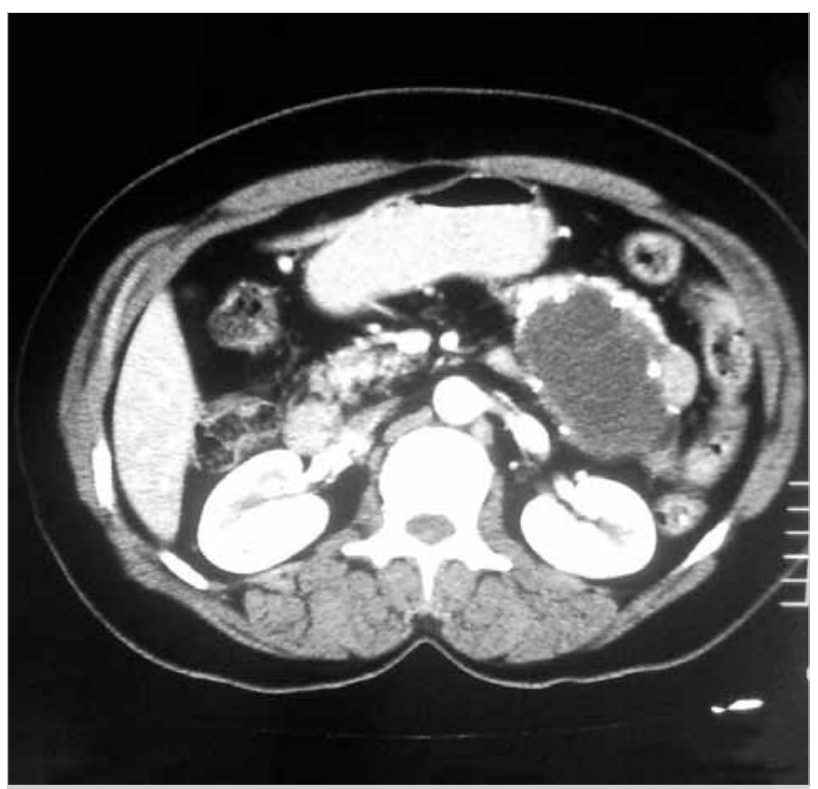

Figure 1. The preoperative abdominal CT of the first case showing a large cystic mass in the pancreas

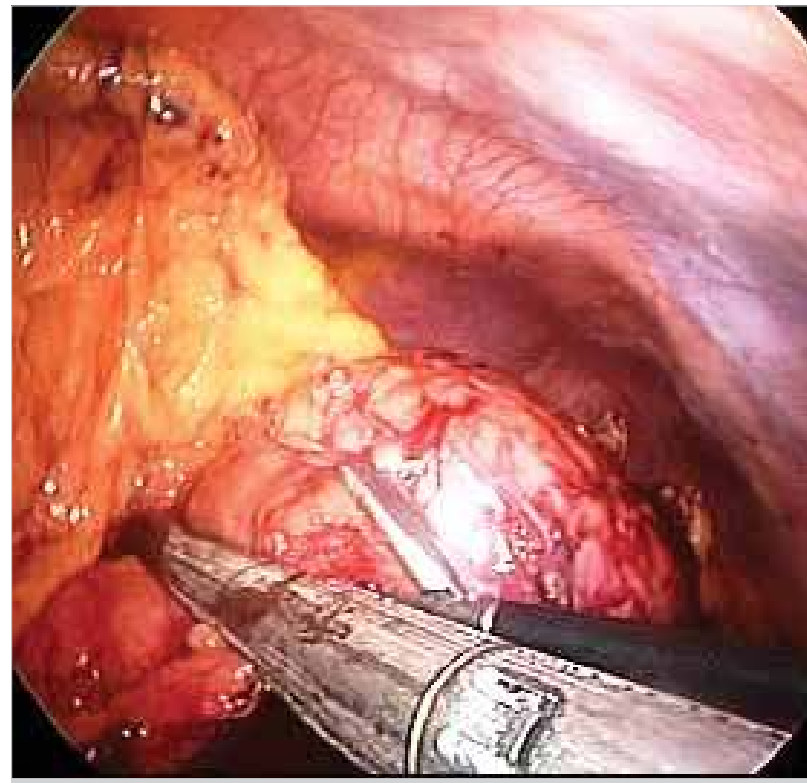

Figure 2. Transection of the pancreas with Endo GIA stapler

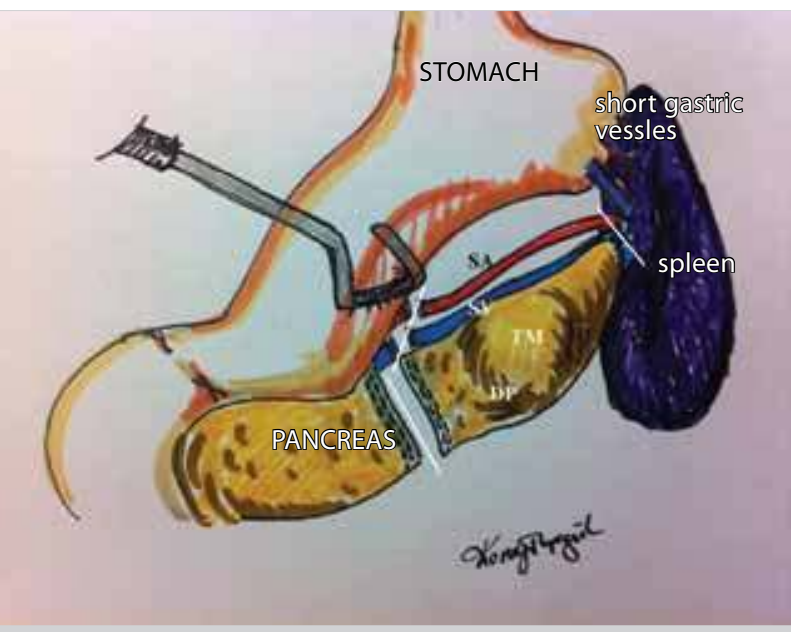

Figure 3. SPLDP with preservation of the short gastric vessels. (SV: splenic vein, SA: splenic artery, DP: distal pancreas, TM:tumoral mass, white lines: line of resection

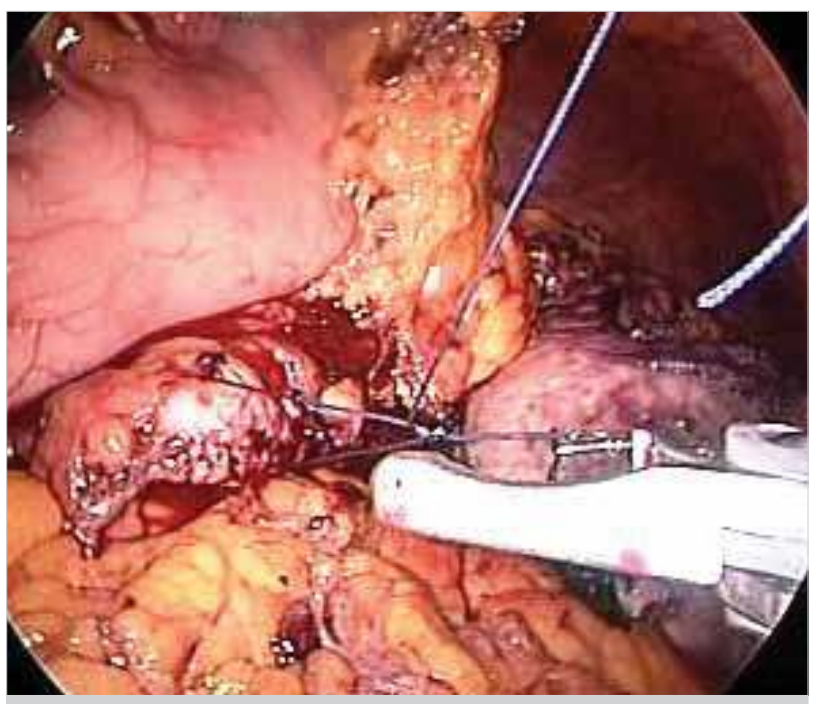

Figure 4. Additional suture replacement to the pancreatic stump with Endostich (Covidien) 


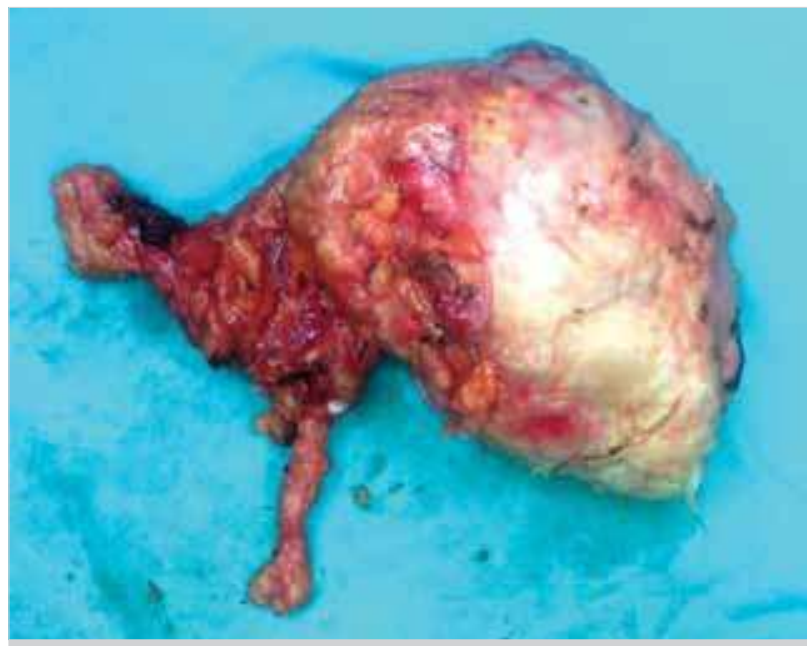

Figure 5. Cystic mass resected with the tail of the pancreas

$6^{\text {th }}$ postoperative month. Her follow-up period of 18 months was uneventful.

\section{Case 2}

A 75 year old female complained of bloating and constipation. The abdominal CT showed a well-defined, $35 \times 32 \mathrm{~mm}$ lesion in the pancreatic tail, with a differential diagnosis of island cell tumor (Figure 7). She had a prior thyroidectomy and c-section, she was currently receiving medication for hypertension. Routine pre-operative examinations and test were done.

The patient underwent a SPLDP as described in the first case. The pancreatic stump was re-enforced with intracorporeal sutures over the staple line using 2/0 polypropylene, for prophylaxis of pancreatic fistula. The operation time was $135 \mathrm{~min}$ utes. Her drain was removed on the $2^{\text {nd }}$ postoperative day, she had complaints of abdominal distension on the $4^{\text {th }}$ day and the ultrasonography revealed a fluid collection in the pancreatectomy site, in the dimension of $5 \times 3 \mathrm{~cm}$. This collection was followed-up with no requirement for an additional intervention. The patient was discharged in a week after conservative therapy. Her ultrasonography done after 2 weeks showed that the collection was regress, the $3^{\text {rd }}$ month control revealed no pathology within the abdomen, the spleen was normal. The pathology was reported as serous cystic adenoma. Her followup of 12 months was uneventful.

\section{DISCUSSION}

Gagner and Pomp (1) performed the first laparoscopic pancreas resection in humans. An increasing number of cases and studies regarding laparoscopic pancreatic resection have been reported in the literature since then (6). Although the comparative studies include small numbers of cases it is stated that in comparison to open surgery LDP shows all advantages of minimally invasive procedures like shorter length of hospital stay, quicker return to daily activities, earlier oral intake and less requirement of analgesics $(3,7)$. Jayaraman et al. (4) reported their results on comparing 107 LDP with 236

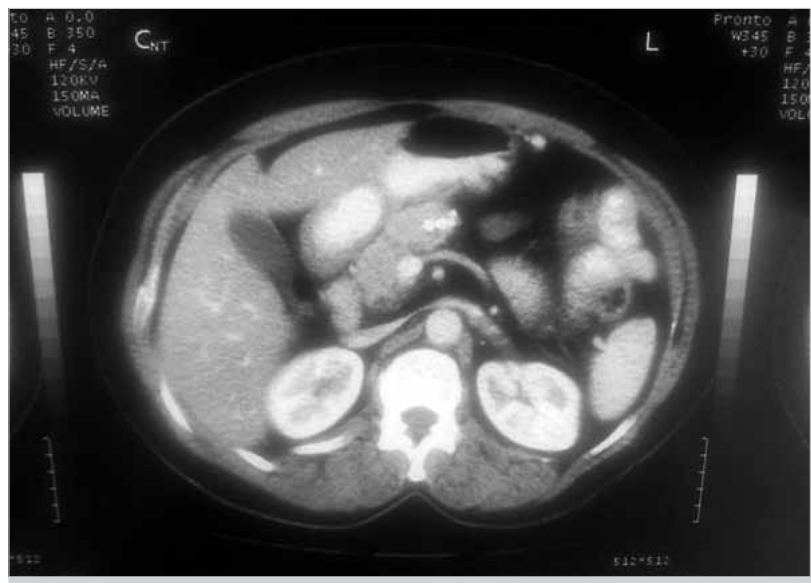

Figure 6. Postoperative follow-up CT of the first case

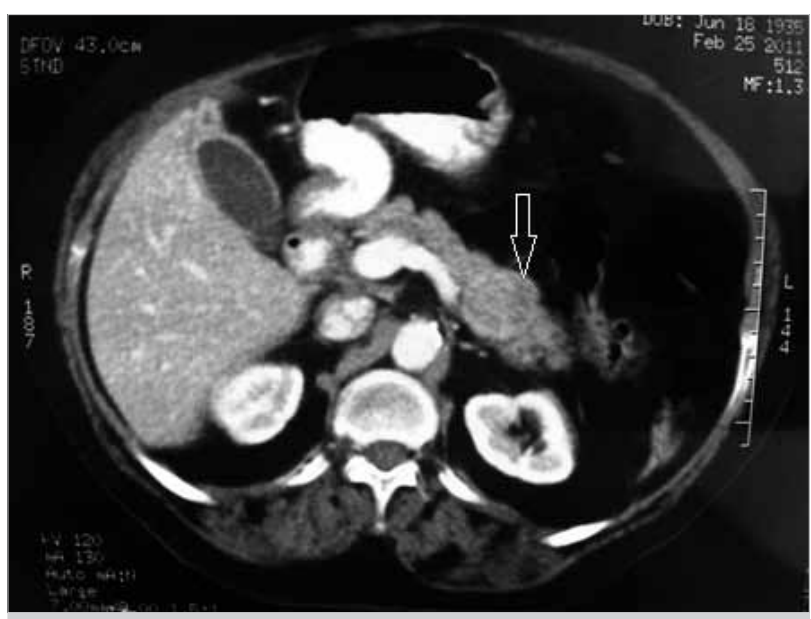

Figure 7. Preoperative CT of the second case (white arrow: lesion)

open distal pancreatectomies, and found out that the length of hospital stay and blood loss (150 cc vs. 350 cc) was significantly less in the laparoscopic group, but the operation time was longer (193 min vs. $164 \mathrm{~min}$ ). The operation time in our two cases was 190 and 135 minutes.

In our first case, the pathologic evaluation revealed a cysticsolitary papillary neoplasm. Frantz first defined this very rare tumor in 1959 (8). Cystic-papillary neoplasm may have a malignant behaviour although they are generally benign. Their frequency in exocrine pancreas tumors is $1-2 \%$. They are 10 times more frequent in females. They may be seen during any period of life, being most frequent in the $3^{\text {rd }}$ decade (9). The other case was diagnosed as serous cystic adenoma. Based on the facts that, we do not have the resources to perform endoscopic ultrasonography (EUS) and EUS guided biopsy in our clinics, the old age of the patient and the dimension of the lesion surgery was planned directly. Hwang et al. (10) state that, minimally invasive surgery should be considered as the first treatment option in tumors less than $2 \mathrm{~cm}$ in an advanced age or in tumors that are $3-5 \mathrm{~cm}$ in size even when they are asymptomatic, as these carry malignant potential, no matter how low the malign potential is in serous cystic adenomas. 
Distal pancreatectomy is an easier laparoscopic approach than pancreatoduodenectomy with its lack of requirement of a biliary or enteric anastomosis. During this operation, attention must be given to preservation of the splenic artery and vein. Since the spleen also receives supply from the short gastric vessels, the spleen can still be preserved even when these vascular structures are injured or in technical. This technique is named as Warshaw technique when the operation is done with ligation of the splenic vessels (11). In parallel, in our cases although the splenic vein and the artery are ligated there were no problems in spleen vascularization during the operation or any spleen abscess or infarcts during follow-up. In malignancies, distal pancreatectomy must be performed together with splenectomy, based on oncologic principals.

Laparoscopic distal pancreatectomy is accepted as a safe minimal invasive technique especially applicable to benign tumors in many studies, nevertheless pancreatic fistulas remain to be an issue. In different series high rates varying between $8-28 \%$ have been reported $(12,13)$. This ratio is high in comparison to open series (14). Baker et al. (12) related this high ratio to their not performing additional steps to close the pancreatic duct on the stapler line and in their series the rate of fistula in open surgeries was $14 \%$, and in LDP $22 \%$. Kleef et al. (15) showed that the fistula rate is highest in the group that pancreatic stump was closed with stapler as compared to sutures, seromuscular patch or pancreaticojejunal anastomosis. In another study usage of seemguard assisted stapler is shown to decrease fistula rates (16). In our cases, in order to prevent formation of pancreatic fistula, after transection of the pancreas with an Endo GIA stapler, we used a third layer of sutures with either 'Endostich' or intracorporeal polypropylene sutures. Although there were only two cases, we did not encounter any pancreatic fistulas. In studies and our practice, the main concern is the technique of pancreatic stump closure. Nevertheless, it is well documented in the literature that patient related factors such as obesity, presence of diabetes and cigarette smoking are contributing factors for the formation of pancreatic fistula (17).

Laparoscopic procedures have the advantage of smaller incisions but in general, these incisions need to be enlarged for the removal/extraction of the specimen. In our first case, we aspirated the contents of the cyst of $7 \times 8 \mathrm{~cm}$ size within the 'endobag', therefore shrinking the volume. The port size was $18 \mathrm{~mm}$. The degenerated cyst and the soft pancreatic tissue were extracted from this incision without necessity of further enlargement. One of the main reasons for conversion to open surgery is tumor size $(>3) \mathrm{cm}$. We believe this practical approach to cystic lesions will be helpful in this type of laparoscopic surgery (4).

\section{CONCLUSION}

Laparoscopic distal pancreatectomy is a safe method with the benefits of laparoscopic surgery. The short gastric vessels will vein are ligated. The procedure can be completed without further enlarging the incision by the technique we described, with aspiration of the cystic masses within the endobag during extraction.

Conflict of Interest: No conflict of interest was declared by the authors.

Peer-review: Externally peer-reviewed.

Informed Consent: Written informed consent was obtained from patients who participated in this case.

Author Contributions: Concept - K.T.; Design - K.T.; Data Collection and/or Processing - K.T., B.K., T.K.; Analysis and/or Interpretation - K.T., S.S.Y.; Writer - K.T.

\section{REFERENCES}

1. Gagner M, Pomp A. Laparoscopic pylorus-preserving pancreatoduodenectomy. Surg Endosc 1994; 8: 408-410.

2. Papavramidis T, Papavramidis S. Solid pseudopapillary tumors of the pancreas: review of 718 patients reported in English literature. J Am Coll Surg 2005; 200: 965-972.

3. Matsumoto T, Shibata K, Ohta M, Iwaki K, Uchida H, Yada K, et al. Laparoscopic distal pancreatectomy and open distal pancreatectomy: a nonrandomized comparative study. Surg Laparosc Endosc Percutan Tech 2008; 18: 340-343.

4. Jayaraman S, Gonen M, Brennan MF, D'Angelica MI, DeMatteo $\mathrm{RP}$, Fong $\mathrm{Y}$, et al. Laparoscopic distal pancreatectomy: evolution of a technique at a single institution. J Am Coll Surg 2010; 211: 503-509.

5. Carrère $\mathrm{N}$, Abid $\mathrm{S}$, Julio $\mathrm{CH}$, Bloom $\mathrm{E}$, Pradère B. Spleen-preserving distal pancreatectomy with excision of splenic artery and vein: a case-matched comparison with conventional distal pancreatectomy with splenectomy. World J Surg 2007; 31: 375-382.

6. Mabrut JY, Fernandez-Cruz L, Azagra JS, Bassi C, Delvaux G, Weerts J, et al. Laparoscopic pancreatic resection: results of a multicenter European study of 127 patients. Surgery 2005; 137: 597-605.

7. Kneuertz PJ, Patel SH, Chu CK, Fisher SB, Maithel SK, Sarmiento $J M$, et al. Laparoscopic distal pancreatectomy: trends and lessons learned through an 11-year experience. J Am Coll Surg 2012; 215: 167-176.

8. Frantz VK. Tumors of pancreas. Atlas of tumor pathology Washington, DC Armed Forces Institute of Pathology; 1953; 32-33.

9. Papavramidis TS, Pliakos I, Michalopaulos N, Karayanopoulou G, Kesisoglou I, Tzioufa V, et al. Asolid pseudo-papillary tumor of the pancreas. Ann Gastroenterol 2008; 21: 242-244.

10. Hwang HK, Kim H, Kang CM, Lee WJ. Serous cyst adenoma of the pancreas: appraisal of active surgical strategy before it causes problems. Surg Endosc 2012; 26: 1560-1565.

11. Warshaw AL. Conservation of the spleen with distal pancreatectomy. Arch Surg 1988; 123: 550-553.

12. Baker MS, Bentrem DJ, Ujiki MB, Stocker S, Talamonti MS. A prospective single institution comparison of peri-operative outcomes for laparoscopic and open distal pancreatectomy. Surgery 2009; 146: 635-643.

13. Melotti G, Butturini G, Piccoli M, Casetti L, Bassi C, Mullineris B, et al. Laparoscopic distal pancreatectomy: results on a consecutive series of 58 patients. Ann Surg 2007; 246: 77-82. 
14. Lillemoe KD, Kaushal S, Cameron JL, Sohn TA, Pitt HA, Yeo CJ. Distal pancreatectomy: indications and outcomes in 235 patients. Ann Surg 1999; 229: 693-698.

15. Kleeff J, Diener MK, Z'graggen K, Hinz U, Wagner M, Bachmann $\mathrm{J}$, et al. Distal pancreatectomy: risk factors for surgical failure in 302 consecutive cases. Ann Surg 2007; 245: 573-582.
16. Yamamoto $M$, Hayashi MS, Nguyen NT, Nguyen TD, McCloud S, Imagawa DK. Use of Seamguard to prevent pancreatic leak following distal pancreatectomy. Arch Surg 2009; 144: 894-899.

17. Nathan $\mathrm{H}$, Cameron JL, Goodwin $\mathrm{CR}$, Seth AK, Edil BH, Wolfgang $\mathrm{CL}$, et al. Risk factors for pancreatic leak after distal pancreatectomy. Ann Surg 2009; 250: 277-281. 